\title{
Habilidades sociais e coworking: Possibilidade ou necessidade?
}

\author{
Habilidades sociales y coworking: posibilidad o necesidad?
}

\author{
Social skills and coworking: possibility or necessity?
}

\author{
ORCID: 0000-0001-7914-8208 \\ E-mail: luis.aub02@gmail.com
}

Marina Pante

Universidade de Santa Cruz do Sul (UNISC), Santa Cruz do Sul - RS/Brasil

ORCID: 0000-0002-5551-8427

E-mail: marinapante@unisc.br

\begin{abstract}
Resumo
O coworking é uma tendência mundial que vem crescendo no Brasil. Mais que um local de trabalho, é um ambiente de colaboração, criatividade e inovação e que favorece a networking. Porém para que a pessoa possa usufruir dessas possibilidades, é necessário que tenha algumas habilidades sociais desenvolvidas e aplicadas. Neste artigo, se buscou entender como se dão as relações interpessoais no coworking, como é a qualidade dessas relações e se dependem de a pessoa possuir um repertório de habilidades sociais previamente desenvolvidas ou se o coworking pode ser um local de desenvolvimento de habilidades sociais. Para isto, realizaram-se dez entrevistas semiestruturadas com profissionais de diferentes áreas que trabalham num coworking, convidando pessoalmente cada um deles. Estas entrevistas que com foram exploradas através da Análise de Conteúdo de Bardin (1977), sob as categorias de: (1) habilidades sociais, (2) comportamentos não-assertivos/agressivos, (3) visão de coworking e (4) outros. Faz-se uma revisão sobre as principais características do coworking, que é apontado como um local que favorece o sentimento de comunidade, além de um entendimento da importância das habilidades sociais. Como resultados, verificou-se que é necessário tanto um desenvolvimento prévio de habilidades sociais para se integrar ao coworking quanto a disposição do profissional para desenvolver suas habilidades sociais na convivência com outras pessoas que compartilham o mesmo espaço. Conclui-se que este pode ser um campo de atuação para o psicólogo no sentido de auxiliar no desenvolvimento de habilidades sociais.
\end{abstract}

Palavras-chaves: Habilidades sociais; Coworking; Relações interpessoais.

\section{Resumen}

El coworking es una tendencia mundial que está creciendo en Brasil. Más que un lugar de trabajo, es un entorno colaborativo, creativo e innovador que favorece la creación de redes. Sin embargo, para que la persona disfrute de estas posibilidades, es necesario tener algunas habilidades sociales desarrolladas y aplicadas. En este artículo, buscamos comprender cómo se producen las relaciones interpersonales en el coworking, cómo es la calidad de estas relaciones y si dependen de tener un repertorio de habilidades sociales previamente desarrolladas o si el coworking puede ser un lugar para desarrollar habilidades sociales. Para ello, se realizaron diez entrevistas semiestructuradas con profesionales de diferentes áreas que trabajan en un coworking, invitando personalmente a cada uno de ellos. Estas entrevistas con ellos se exploraron a través del Análisis de contenido de Bardin (1977) en las categorías de: (1) habilidades sociales, (2) comportamientos agresivos / no asertivos, (3) visión de coworking y (4) otros. Se hace una revisión de las características principales del coworking, que se señala como un lugar que favorece el sentimiento de comunidad, así como una comprensión de la importancia de las habilidades sociales. Como resultado, se descubrió que es necesario tanto un desarrollo previo de habilidades sociales para integrarse con el coworking como la disposición del profesional para desarrollar sus habilidades sociales en convivencia con otros que comparten el mismo espacio. Se puede concluir que este puede ser un campo para que los psicólogos ayuden en el desarrollo de habilidades sociales.

Palabras clave: Habilidades sociales; Coworking; Relaciones interpersonales. 


\begin{abstract}
Coworking is a worldwide trend that is growing in Brazil. More than a workplace, a collaborative, creative and innovative environment favors networking. However, for the person to enjoy these possibilities, it is necessary to have some social skills developed and applied. In this paper, we sought to understand how interpersonal relationships occur in coworking, what the quality of these relationships is like, and whether they depend on having a repertoire of previously developed social skills or whether coworking can be a place for developing social skills. For this, ten semi-structured interviews were conducted with professionals from different areas working in a coworking, personally inviting each one of them. These interviews with them were explored through Bardin's Content Analysis (1977)
\end{abstract}

under the categories of: (1) social skills, (2) unassertive / aggressive behaviors, (3) coworking view, and (4) others. A review is made of the main characteristics of coworking, which is pointed as a place that favors the feeling of community, as well as an understanding of the importance of social skills. As a result, it was found that both the prior development of social skills to integrate with coworking and the willingness of the professional to develop their social skills in coexistence with others who share the same space is necessary. It has concluded that this may be a field for psychologists to assist in the development of social skills.

Keywords: Social skills; Coworking; Interpersonal relationships.

\section{Introdução}

O coworking é uma opção de local de trabalho cada vez mais visível para pessoas que pretendem empreender, mas não gostariam de permanecer sozinhas em um home office ou mesmo arcar com o ônus de alugar uma sala comercial. A criação dos espaços de coworking é muito recente, datada em 2005, no Vale do Silício, São Francisco, nos Estados Unidos, como sendo principalmente um espaço compartilhado que possibilita a criatividade e a inovação, onde se dividem desde os custos da manutenção do local até informações e experiências (Gandini, 2015).

É uma tendência que vem crescendo no Brasil, sendo que, segundo o site Coworking Brasil (2018), em 2015 havia apenas 238 espaços e em 2018, até aquele momento, existiam 1194 espaços no território nacional, ou seja, aumentou em mais de cinco vezes esse número em apenas três anos. Esta não é apenas uma tendência no Brasil, mas também no mundo. Nestes espaços compartilhados encontram-se pequenos empresários, profissionais autônomos, freelancers, entre outros trabalhadores que buscam um local que dê um aspecto mais profissional para seu trabalho, com menores custos, e que favoreçam networking, a colaboração e a criatividade (Nakao \& Mussi, 2018).

No local são compartilhados os recursos (internet, luz), conhecimentos e experiências e o espaço físico. Isso contribui para a inovação, a criatividade, a cooperação, a criação conjunta de soluções, quando necessário, além de aumentar a rede de contatos e tornar cada um dos profissionais como referência para os outros que estão no local. Esses espaços tornam-se locais de criatividade e inovação no momento em que se fomenta a interação entre as pessoas (Nakao \& Mussi, 2018).

Entende-se que para que a criatividade seja impulsionada e para que haja colaboração, faz-se necessário que cada uma das pessoas que integra o coworking, os chamados coworkers, tenham desenvolvidas as suas habilidades sociais. Por habilidades sociais pode-se entender a capacidade de emitir e compreender os comportamentos adequados a cada situação, sendo que alguns comportamentos assertivos como empatia e capacidade de negociação são fundamentais para uma interação social satisfatória (Caballo, 2003).

Também pode-se compreender
habilidades sociais como sendo os
comportamentos socialmente valorizados a um
determinado local, tempo e a um certo grupo de
pessoas, que será entendido por esse grupo de
forma a gerar resultados positivos para o
emitente. Esses comportamentos podem ser
sempre descritos e também podem ser
avaliados como positivos ao se empregá-los em
tarefas interpessoais, buscando sempre que eles


não sejam nem agressivos, nem passivos, mas sim assertivos (Del Prette \& Del Prette, 2017).

Através das habilidades sociais o indivíduo pode expressar sentimentos, desejos, opiniões e comportamentos adequados à interação social, respeitando esses mesmos comportamentos nos outros, sendo que esta forma de interação previne problemas futuros e soluciona problemas imediatos (Caballo, 2003). Ou seja, a habilidade social é a capacidade de o indivíduo reagir da melhor maneira possível com as outras pessoas e com o ambiente que o cerca, expondo aquilo que senti e pensa, respeitando a exposição do outro e também o local onde está. A partir disso, pode-se dizer que todos têm comportamentos mais ou menos habilidosos para determinada situação.

Os comportamentos podem ser classificados em três tipos: assertivos, que são a exposição dos próprios sentimentos e necessidades, respeitando estas características nos outros; não assertivos, que são comportamentos em que o sujeito viola seus próprios direitos ao não ser capaz de expressar honestamente seus sentimentos; e agressivos, que são em defesa dos próprios direitos, geralmente de forma desonesta, e sem considerar os direitos dos outros (Caballo, 2003, pp. 361-364)

Estes três tipos de comportamentos fazem parte da vida de todas as pessoas. Por vezes têm-se comportamentos mais assertivos, em outros momentos têm-se mais comportamentos não-assertivos e em alguns momentos têm-se comportamentos agressivos. Normalmente uma dessas formas é a predominante em cada um dos indivíduos. É possível aprender e desenvolver assertividade, pois dessa forma pode-se relacionar melhor com os demais (Caballo, 2003).

Um outro conceito importante dentro da área das habilidades sociais é o de competência social, que pode ser entendido como uma forma de se avaliar a aplicação das habilidades sociais em uma tarefa interpessoal. Uma pessoa socialmente competente consegue atingir seus próprios objetivos de forma ética, respeitando as outras pessoas que estão a sua volta e a cultura a qual pertence (Del Prette \& Del Prette, 2017).

Diversas habilidades sociais são necessárias no ambiente de trabalho e dentre algumas delas temos a capacidade de fazer pedidos, lidar com conflitos e manejar o estresse, pois nenhum trabalho é totalmente isolado e sem interação social, quando se está trabalhando, está-se relacionando (Del Prette \& Del Prette, 2001). Isto serve para os espaços coworking, pois qualquer profissional trabalhe por conta própria estará em um espaço coletivo de trabalho, e será necessário interagir com os outros profissionais que dividem este mesmo local.

Diante dessa inovação na forma de se trabalhar, fazem-se os seguintes questionamentos: como se dão as relações interpessoais dentro desse espaço de trabalho compartilhado? Estas dependem de que seus coworkers possuam habilidades sociais, ou eles podem melhorar seu repertório de habilidades sociais com o tempo e a convivência? E como é a qualidade das relações interpessoais nesse espaço?

A partir destes questionamentos, esta pesquisa buscou compreender como se dão as relações interpessoais em um espaço coworking para que se pudesse verificar como estes coworkers percebiam suas relações interpessoais naquele local. Ainda não existem artigos que tratem exatamente desta temática das habilidades sociais nos espaços de trabalho compartilhado.

\section{Método}

A presente pesquisa adotou metodologia qualitativa e se deu através de entrevistas semiestruturadas com dez coworkers, que é a forma como as pessoas que trabalham em um coworking se reconhecem entre si, utilizando um questionário contendo 23 perguntas elaboradas pelo pesquisador. As entrevistas - que estavam divididas entre dados de informação, perguntas sobre a visão de 
coworking, perguntas sobre as relações interpessoais e perguntas sobre as habilidades sociais do entrevistado - foram conduzidas no próprio local de trabalho, em um espaço coworking em uma cidade no centro do estado do Rio Grande do Sul, durante o horário comercial de funcionamento do espaço. Os profissionais foram convidados a participar da entrevista, e aos que se interessaram, foi explicado o funcionamento e objetivo da pesquisa.

\section{Participantes}

Foram entrevistados cinco homens e cinco mulheres, escolhidos por conveniência, e pela respectiva disponibilidade de cada um deles, sendo que os dez convidados aceitaram participar da pesquisa. No espaço coworking circulam em média trinta coworkers por mês. São profissionais liberais, tais como publicitários e programadores, dentre outros, que se utilizam do espaço.

Foram considerados também como critérios de inclusão na pesquisa ser maior de 18 anos e autorizar a sua participação através da assinatura do Termo de Consentimento Livre e Esclarecido desta pesquisa. Além disso, só foram incluídos os participantes que utilizam as dependências do coworking por pelo menos um turno por semana. Todos os participantes e o local tiveram suas identidades mantidas em sigilo assim como a garantia do anonimato em relação às respostas fornecidas a qualquer momento da pesquisa.

Dentre os entrevistados do coworking, havia três pessoas que trabalhavam com programação, dois profissionais de marketing digital, dois designers de interior, um corretor de consórcios, um assistente comercial e um empresário. As idades variaram de 26 a 48 anos, sendo que a idade média dos entrevistados foi de 34,1 anos. As mulheres têm média etária de 36,6 anos, já os homens possuem uma média de 31,6 anos, o que permite entendermos que as pessoas que trabalham em um coworking já estão na sua maturidade, e que é onde existe também o maior número de empreendedores, na faixa dos
25 a 44 anos de idade (Global Entrepreneurship Monitor, 2014).

O grau de escolaridade médio é alto, sendo que três possuem pós-graduação; quatro possuem ensino superior completo; dois possuem ensino superior incompleto. Apenas um dos entrevistados possuía somente ensino médio completo, mas este, assim como outros, procurou diversos cursos de atualização em sua área de atuação, a qual já trabalha há bastante tempo.

\section{Instrumentos}

Sendo uma pesquisa com seres humanos, foi necessária a aceitação do Comitê de Ética da Universidade de Santa Cruz do Sul, além de que o participante lesse, concordasse e assinasse o Termo de Consentimento Livre e Esclarecido, de maneira que este fosse o demonstrativo do compromisso ético dos pesquisadores de guardar sigilo da identidade dos sujeitos entrevistados. Este projeto de pesquisa foi registado na Plataforma Brasil sob o número CAAE: 09607518.9.0000.5343.

Quando se trabalha com pesquisa qualitativa, o importante é permitir que o participante tenha a escolha de falar um pouco ou discorrer sobre o tema. As respostas não devem ser induzidas de nenhuma forma pelo pesquisador, que deve permanecer neutro e aceitar quaisquer outras questões que possam surgir no decorrer da entrevista. Este tipo de pesquisa deve ocorrer no local onde se encontram os sujeitos pesquisados, pois dessa forma $\mathrm{o}$ pesquisador pode aprofundar sua compreensão do meio, vivenciando-o ao realizar a entrevista. A interpretação do pesquisador sobre os dados colhidos também é levada em conta, ou seja, a análise realizada das gravações das entrevistas e também a observação das relações dentro do coworking antes e depois da entrevista (Minayo, 2014).

\section{Procedimentos}

Todas as entrevistas foram transcritas de forma manual, ouvindo um pequeno trecho, pausando e escrevendo fielmente o que se 
ouvia, salvo em momentos em que foi impossível decifrar a fala do entrevistado. Após a transcrição, foi feita a categorização das falas dos entrevistados, utilizando-se a Análise de Conteúdo com foco qualitativo, que leva em conta o significado e a intenção que o sujeito atribui às suas relações, atos e estruturas sociais (Minayo, 2014), que visa realizar o entendimento do conteúdo da mensagem através de procedimentos objetivos e sistemáticos, buscando a inferência, ou seja, o entendimento do real significado das mensagens que os atores de um contexto expressam e vivem (Bardin, 1977).

A Análise de Conteúdo, está dividida em três fases principais, sendo elas a préanálise, a exploração do material, e a parte final, composta pelo tratamento dos resultados, a inferência e a interpretação (Bardin, 1977). Estas três fases serão explicadas a seguir, juntamente com sua aplicação.

A pré-análise é o início da organização propriamente dita, onde os materiais são separados para que então sejam analisados, sendo que também é o momento em que o pesquisador formula hipóteses e as categorias que vão nortear a interpretação do material (Bardin, 1977). Os documentos escolhidos foram as entrevistas semiestruturadas que foram previamente realizadas com os coworkers e posteriormente transcritas.

Segundo Bardin (1977), a hipótese seria uma afirmação temporária que pode vir a se confirmar, e já durante as entrevistas foram levantadas algumas hipóteses, sendo que a primeira delas é de que as pessoas para se integrarem ao coworking precisam já ter algumas habilidades sociais desenvolvidas, tais como habilidades de comunicação e de civilidade (Del Prette \& Del Prette, 2017). Outra hipótese é que essa integração e a permanência do coworker no espaço dependem também desse desenvolvimento de habilidades sociais, além do entendimento de que não é apenas um lugar com custo mais baixo, mas um local que oportuniza o crescimento e desenvolvimento tanto pessoal quanto da própria empresa ou função exercida, no caso de profissionais autônomos. Porém, isso requer que a pessoa se adeque às regras do local, desenvolvendo, por exemplo, a habilidade de civilidade no sentido de não falar alto no coworking, respeitando assim todos os outros colegas do mesmo espaço.

A criação de categorias se dá a partir dos objetivos do estudo, sendo que foi é realizado um recorte do texto conforme este se encaixe em cada uma das categorias (Bardin, 1977). Estas categorias precisam seguir algumas normas para que o trabalho de categorização seja mais preciso, sendo que as regras devem ser claras para se realizar a inclusão ou exclusão de um trecho do texto em uma das categorias, elas devem se excluir entre si e ser específicas, contemplando quase todo o conteúdo que é apresentado pelo material deixando para a categoria "outro" o que é residual, que não se encaixa nas categorias selecionadas. Toda essa classificação deve ser feita de forma objetiva e não depender da interpretação do analista (Carlomagno \& Rocha, 2016). Desta forma, criaram-se as seguintes categorias: (1) habilidades sociais, (2) comportamentos não-assertivos/agressivos, (3) visão de coworking e (4) outros.

$\mathrm{Na}$ primeira categoria denominada "habilidades sociais" se buscaram as falas em que os entrevistados relatavam estar aplicando alguma habilidade social (Del Prette \& Del Prette, 2017), que se traduz por um comportamento assertivo, onde existe o respeito ao próximo e por si mesmo, defendendo o próprio direito sem interferir no do outro (Caballo, 2003). A segunda categoria, "comportamentos não-assertivos/agressivos", abarcou as falas em que os entrevistados mencionavam comportamentos passivou ou agressivos, tanto em relação a si mesmos quanto ao próximo (Caballo, 2003), ou seja, comportamentos que não são socialmente hábeis, que interferem de forma negativa ao entrevistado e às pessoas a sua volta (Del Prette \& Del Prette, 2017). Esses comportamentos poderiam ser tanto no coworking quanto em situações fora deste local. 
$\mathrm{Na}$ terceira categoria, "visão de coworking", buscou-se os relatos de sentimentos e pensamentos (Beck, 2013) do entrevistado em relação ao coworking, o que descartava todos os comportamentos já catalogados nas duas categorias anteriores. Por fim, na categoria "outros" foram inseridas as outras falas que não correspondiam às três primeiras categorias e que não tinham conexão direta com o tema proposto, assim como os dados iniciais de apresentação do entrevistado, como nome, idade e profissão e comentários acerca das respostas a estes dados.

Após a seleção das categorias e a transcrição, foi feita a categorização de cada uma das entrevistas, o que corresponde a etapa da preparação do material para a exploração (Bardin, 1977). Para cada entrevista utilizou-se uma tabela com quatro colunas, uma para cada categoria, e então foram copiados trechos da entrevista e colados nas células das colunas correspondentes ao assunto tratado. Quando as falas eram muito longas, eram cortadas por tamanho e por assunto, de forma que não ficassem trechos muito longos da entrevista na mesma célula.

Após esta primeira seleção, foram ainda separadas as falas do entrevistador, as quais foram transcritas na categoria "outros" e então fez-se a contagem do número de falas que eram apenas do entrevistado. Utilizaram-se duas tabelas para catalogar o sexo, idade, profissão, escolaridade e a quantidade de falas em cada uma das categorias.
A segunda parte se deu realizando a leitura por categorias, iniciando pela categoria de habilidades sociais, de forma que se liam apenas as falas relacionadas a categoria analisada. Assim, buscou-se qual era a classe da respectiva habilidade social mencionada segundo o Portfólio de Habilidades Sociais (Del Prette \& Del Prette, 2017), passando por cada um dos entrevistados.

Já a segunda categoria, de comportamentos não-assertivos/agressivos, foram averiguadas quantas falas estavam relacionadas a não-assertividade ou a agressividade (Caballo, 2003), permitindo também entender um pouco melhor a forma de funcionamento dos coworkers. Por fim, a terceira categoria, visão de coworking, buscouse identificar quais os sentimentos e pensamentos dos entrevistados em relação ao coworking, o que reflete as ideias e opiniões dos entrevistados (Bardin, 1977).

\section{Resultados}

Analisando inicialmente a classificação numérica da quantidade de trechos de falas relacionados a cada uma das categorias, observa-se que, em geral, as mulheres expressaram mais falas relacionadas a habilidades sociais, e que os homens, em geral, referenciaram mais comportamentos nãoassertivos/agressivos. Isto indica que os homens podem ter uma menor competência social, ou seja, um menor aproveitamento das relações em benefício mútuo baseado (Del Prette \& Del Prette, 2017).

Tabela 1

Relação sexo, idade e números de falas nas categorias

\begin{tabular}{|c|c|c|c|c|c|c|}
\hline Sexo & Idade & $\begin{array}{l}\text { Habilidades } \\
\text { Sociais } \\
\end{array}$ & $\begin{array}{c}\text { Comportamentos não-assertivos/ } \\
\text { agressivos }\end{array}$ & $\begin{array}{l}\text { Visão de } \\
\text { Coworking }\end{array}$ & Outros & $\begin{array}{l}\text { Total de falas } \\
\text { do entrevistado }\end{array}$ \\
\hline Fem. & 46 & 60 & 10 & 104 & 47 & 221 \\
\hline Fem. & 39 & 32 & 10 & 31 & 50 & 123 \\
\hline Masc. & 48 & 21 & 26 & 22 & 47 & 116 \\
\hline Fem. & 35 & 17 & 5 & 43 & 29 & 94 \\
\hline Masc. & 25 & 20 & 2 & 39 & 27 & 88 \\
\hline Fem. & 34 & 25 & 13 & 20 & 13 & 71 \\
\hline Masc. & 26 & 12 & 18 & 10 & 30 & 70 \\
\hline Fem. & 29 & 17 & 5 & 23 & 18 & 63 \\
\hline Masc. & 31 & 7 & 8 & 16 & 22 & 53 \\
\hline Masc. & 28 & 8 & 9 & 11 & 12 & 40 \\
\hline
\end{tabular}


As mulheres apresentaram número de falas sobre o coworking muito maior que a dos homens, elas se identificam mais com o fato de serem coworkers e com as vantagens imediatas, como acolhimento, atenção e carinho que fazem parte da dinâmica do espaço. Os homens, como no exemplo a seguir, colocam muito mais o menor custo como um fator determinante para aderir ao coworking. Os nomes citados nas falas foram substituídos a fim de preservar o sigilo das pessoas e instituições citadas pelos entrevistados.

É que antes a gente tinha lá o endereço tal por questão de custo também, mas com o tempo não tinha necessidade de pagar muito mais caro do que ficar num espaço coworking ou trabalhar de casa mesmo né, pra nós pelo menos não compensava ficar lá por um preço 3, 4 vezes mais alto, $e$ como a gente não precisa de eu espaço muito complexo, a gente acabou optando por vir pra cá, como é um espaço legal, tive oportunidade de crescer também, tem bastante trabalho de TI que o pessoal da área de TI vem e faz ai, então a gente optou por vir.
No total, foram recortados 219 trechos de falas sobre habilidade sociais, 106 trechos sobre comportamentos nãoassertivos/agressivos, 319 trechos sobre a visão de coworking (totalizando 644), e 295 trechos sobre outros assuntos. Ao todo foram 939 trechos de entrevistas, e por serem a maioria dos trechos relacionados as categorias, entende-se que é válida segundo a Análise de Conteúdo (Bardin, 1977).

No total das falas relacionadas a categoria habilidades sociais, foi possível identificar que a maioria das falas estava relacionada as habilidades sociais (HS) assertivas (43\%), seguida pelas HS de comunicação (20\%), e HS de Civilidade, (10\%) (Del Prette \& Del Prette, 2017). As demais habilidades sociais, somaram $27 \%$ das falas, sendo que a HS coordenar grupo foi mencionada apenas uma vez, em função de que apenas um dos entrevistados tinha essa necessidade, já que realizava gestão conjunta de projetos, e contava com a parceria de diferentes profissionais para a realização do trabalho. A tabela a seguir apresenta estes dados.

Tabela 2

Numeração de falas da categoria habilidades sociais

\begin{tabular}{|c|c|c|c|c|c|c|c|c|c|c|c|}
\hline \multirow{2}{*}{ Habilidades Sociais } & \multicolumn{10}{|c|}{ Participantes } & \multirow{2}{*}{ Total } \\
\hline & Fem. & Masc. & Fem. & Masc. & Masc. & Fem. & Fem. & Masc. & Masc. & Fem. & \\
\hline Assertivas & 7 & 11 & 28 & 3 & 3 & 16 & 7 & 6 & 5 & 8 & 94 \\
\hline Comunicação & 9 & 3 & 9 & 2 & 2 & 6 & 4 & 5 & 0 & 4 & 44 \\
\hline Civilidade & 2 & 0 & 10 & 1 & 1 & 1 & 3 & 2 & 1 & 2 & 23 \\
\hline Falar em público & 1 & 2 & 2 & 1 & 1 & 2 & 1 & 3 & 0 & 1 & 14 \\
\hline Empatia & 1 & 0 & 1 & 0 & 0 & 6 & 0 & 0 & 1 & 1 & 10 \\
\hline Expressar afeto e intimidade & 2 & 1 & 2 & 0 & 0 & 0 & 2 & 2 & 0 & 1 & 10 \\
\hline Fazer e manter amizade & 2 & 1 & 4 & 0 & 0 & 1 & 0 & 0 & 0 & 0 & 8 \\
\hline $\begin{array}{l}\text { Manejar conflitos e resolver } \\
\text { problemas interpessoais }\end{array}$ & 0 & 2 & 1 & 0 & 2 & 0 & 0 & 3 & 0 & 0 & 8 \\
\hline Expressar solidariedade & 1 & 0 & 2 & 0 & 3 & 0 & 0 & 0 & 1 & 0 & 7 \\
\hline Coordenar grupo & 0 & 0 & 1 & 0 & 0 & 0 & 0 & 0 & 0 & 0 & 1 \\
\hline
\end{tabular}

Pode-se observar que as HS assertivas são compostas por várias subclasses, como defender direitos, fazer e recusar pedidos, expressar desagrado, manejar críticas, entre outras (Del Prette \& Del Prette, 2017), o que colaborou para que muitas das respostas encaixassem nessa categoria. Porém, isto também mostra o quanto é necessário ser assertivo no coworking, saber respeitar o espaço do outro, o que também fica claro 
através da HS de civilidade, a qual pode ser entendida principalmente como o seguimento das normas cortesia da cultura do local (Del Prette \& Del Prette, 2017). Abaixo temos dois exemplos de HS de Civilidade, onde o coworker respeita uma das regras da cultura que é o silêncio e o respeito pela pessoa que está focada em seu trabalho:

Eu costumo, eu tento não chamar muito quando a pessoa tá trabalhando ali, mas ali na cozinha, no sofá quando o pessoal tá mais relaxado eu acho legal sim, daí a gente vai conhecendo mais gente, daí acaba fazendo umas amizades, trocando umas ideias.

Mas eu acredito que eu espero a oportunidade certa também, as vezes o cara tá trabalhando, vai ter uma oportunidade de conversar com ele, um momento de integração, a hora de chegar $e$ abordar $e$ trocar experiências, mas eu, obviamente, partir isso do nada assim, acredito que nem a pessoa faça isso, não seria o correto, né, então, acho que tem um momento, né.

A HS assertiva foi a única constatada na fala de todos os coworkers, o que demonstra que isto pode ser um pré-requisito para trabalhar no coworking. A seguir temos um exemplo de HS assertiva, na questão de manejo de críticas:

Normal, tipo, depende o nível assim, não, depende, depende, é que assim, afetar, afeta, é obvio que afeta, qualquer um se afeta com crítica, né, a crítica vem quando alguma coisa não está certa, mas eu tento entender, ããa, me colocar literalmente no lugar de quem tá fazendo a crítica e ver se é válida, se não é válida, se é com razão.

A HS falar em público foi mencionada por quase todos os coworkers, apenas um que havia iniciado recentemente relatou que ainda não havia falado em público. O local oferece quinzenalmente um espaço de fala para que cada um dos coworkers possa falar sobre o que faz, sobre algum assunto interessante na sua área, o que é uma iniciativa que estimula esta HS. Abaixo temos um exemplo de HS falar em público onde o coworker usa o humor ao falar sobre o conteúdo do slide de sua apresentação:

Sim, sim, eu fiz um, né, até a fulana brinca, que eu fiz um que eu coordenava sobre programação, e eu fiz um programinha e tinha uma hora um start na tela e tinha uma mensagem que falava se tu poderia comentar ou não, senão era eu falando e eles escutando, mas eu fiz muito mais como uma brincadeira.

Todas as demais HS são mencionadas em algum momento por algum dos coworkers, o que também demonstra a heterogeneidade do perfil de quem integra o coworking. Pode-se afirmar que as relações entre os coworkers são boas, pois segundo os relatos dos participantes, a maioria dos conflitos foram resolvidos de forma assertiva. Alguns desses conflitos foram mais relacionados à administração do coworking, como por exemplo a não abertura de negociação de valores financeiros.

Assim como as HS assertivas foram as mais detectadas nas falas dos entrevistados, na questão dos comportamentos não-assertivos foi o que mais surgiu na segunda categoria, com $77 \%$ das respostas, ficando os comportamentos agressivos com $23 \%$. Nos relatos, a principal dificuldade foi o dizer não e o quanto isto era difícil e penoso, a dificuldade de se valorizar e se respeitar, o que aponta comportamentos nãoassertivos (Caballo, 2003). Um exemplo claro disto é a seguinte fala:

Ah, é difícil, eu tenho muita dificuldade em dizer não, muita dificuldade, eu sempre tento se eu não consigo fazer na, fazer em seguida eu faço mais adiante assim, mas é muito, tenho muita dificuldade, quando não dá mesmo eu tento, eu tento dizer que não consigo, dou uma razão e tento dar uma outra alternativa pra pessoa, 
mas eu sempre tento ajudar, sempre fico me martirizando porque, ai (...).

Os comportamentos agressivos foram relatados pelo menos uma vez por oito dos dez coworkers, mas com uma incidência muito baixa, em geral. Apenas dois dos coworkers tiveram mais falas classificadas como agressivas do que não-assertivas, sendo que, segundo seus relatos, a agressividade era expressa de forma indireta, ou passivoagressiva, o que pode não gerar efeitos negativos imediatos nas relações, mas que pode ter consequências negativas a longo prazo nas relações do indivíduo (Caballo, 2003).

Ao analisar a terceira categoria, visão de coworking, e também baseado na observação do local, algo que chamou a atenção foi a atitude dos coworkers de se importarem com as pessoas que ali chegam, sejam visitantes ou clientes de outros profissionais do local. As pessoas chegam ao coworking e se deparam com os coworkers trabalhando nas várias mesas do espaço compartilhado e nas salas individuais e por vezes não encontram à primeira vista o profissional que procuram, então sempre tem alguém que se dispõe a receber a pessoa e encaminha-la ao profissional que ela busca.

O que que eu digo, natural é entrou alguém aqui dentro, eu sinto que não só da parte delas, mas de qualquer um de nós aqui dentro, seja pra mim ou é um cliente do fulano, ou é um cliente dos guris aqui da empresa tal, a gente quer que a pessoa saia daqui com a melhor experiência possível, sabe, que goste daqui, que volte, então eu sinto que assim, até agora não tenho percebido, não tem ninguém do contra assim, que faz cara feia, que torce o nariz, não, todo mundo é super simpático, seja, ããa, com seus clientes ou com clientes dos outros.

Uma das perguntas elaboradas no questionário era "como são resolvidas as divergências entre os diferentes profissionais que ocupam o mesmo espaço?" As respostas abordaram duas questões distintas: as relações com os outros coworkers e a relação com a administração do coworking. Na questão de divergência com outros profissionais, os entrevistados tinham duas formas predominantes de lidar com a questão: acionando a gerência do coworking, relatando o problema, o que geralmente resultava em uma intervenção da administração do coworking, geralmente mandando um e-mail com um lembrete acerca da solicitação, como demonstrado na fala a seguir:

\section{(...) ããa de uma forma muito tranquila acabou a música, como a gerência usou isso e de que maneira ele deram esse toque, eu lembro que logo depois veio um e-mail, né, "caros colegas, lembramos..." eles foram mui, eles são muito perspicazes nisso, eles não, eles conseguem fazer de uma maneira genérica alguns lembretes e que, no perfil psicológico, de novo volto ao ponto, da pessoa que tá aqui, ela não passa do ponto, (...).}

A segunda forma de lidar com as divergências era conversando com a outra pessoa com quem houve a divergência, segundo o relato de alguns profissionais. Estas falas também demonstram uma capacidade do sujeito em defender seus direitos, mas sem violar os direitos do outro, sendo dessa forma, assertivo (Del Prette \& Del Prette, 2017).

Ao se fazer a pergunta do questionário "o que é um coworking para você?", os entrevistados relataram de forma unânime sempre um sentido de "local de compartilhamento, de dividir" e o quanto esta experiência de compartilhar e a possibilidade de trocas era enriquecedora. Um dos coworkers utilizou a palavra "vivência", relatando de forma positiva o fato de estar em contato com um local diferenciado, o que é demonstrado nas falas a seguir:

Esse compartilhamento parece que tu, essa junção de pessoas tu multiplica conhecimentos, insights e ideias, eu acho que tudo multiplica a partir 
daqui, e sozinho eu acho que tu acaba ficando muito isolado, acho que o coworking é isso (...). Esse compartilhamento parece que tu, essa junção de pessoas tu multiplica conhecimentos, insights e ideias, eu acho que tudo multiplica a partir daqui, e sozinho eu acho que tu acaba ficando muito isolado, acho que o coworking é isso.

(...)Hoje eu tenho um conceito de coworking completamente diferente do que eu tinha antes de vivenciar isso aqui, então assim pra mim é compartilhar, ããa, sim, mas cada um tem sua individualidade e existe assim, ããa, barreiras, sabe, invisíveis, entre todos aqui dentro, que a gente sabe até que ponto respeitar o trabalho, o profissionalismo, que eu não tenho que dar satisfação pra ninguém aqui dentro, se eu saí, se eu entrei, eu compartilho o que eu quero, (...).

Vivencia, tu se relaciona, tu trabalha, tu vive, a gente passa a maior parte do dia da gente no trabalho, né, é vivencia, a gente vive, coworking pra mim é vivência, vivencia, trabalho, $e$ várias outras coisinhas, sabe, compartilhamento, coworking, sabe, mas principalmente uma palavra resume a ideia assim.

O compartilhamento do espaço, foi apontado como positivo, mas ao mesmo tempo desafiador, o que também demonstra a necessidade de auto-observação, que é uma característica da pessoa socialmente competente (Del Prette \& Del Prette, 2017). Pela observação, pode-se apontar que os entrevistados são sim, socialmente competentes:

Coworking pra mim, é sim, tem algumas coisas que tu é obrigado a compartilhar, espaços que tu é obrigado a compartilhar, mas tu só compartilha aquilo que tu quer num coworking, né, porque tem pessoas, eu tinha a visão de fora assim que, não existia, eu tinha muito medo de perder a minha privacidade e tal, e não, sabe, eu vi que não, tu só compartilha aquilo que tu quer, então pra mim é um espaço onde tu compartilha principalmente as pessoas, compartilha principalmente a presença das pessoas, então isso pra mim é um, um resumo assim, o que significa pra mim.

Mas não apenas o compartilhamento de espaços, mas sim as trocas com as pessoas foram apontadas como sendo muito ricas, a experiência de se trabalhar ao lado de profissionais de outras áreas, permitia uma ampliação dos horizontes de cada um dos coworkers, como por exemplo na fala: " $E$, acho que as relações aqui tendem à, a deixar nossas mente mais abertas assim, porque é muita gente diferente convivendo todo dia, acho isso muito legal", o que demonstra que mesmo não trabalhando juntos, a possibilidade de trocar experiência já era muito gratificante $\mathrm{e}$ enriquecedora. Essa troca de experiências também foi relatada como sendo facilitada em momentos específicos, como em confraternizações, no horário do almoço e nas reuniões bissemanais que o espaço tem para que algum dos coworkers exponha seu trabalho, o que é relatado pelos seguintes trechos de falas:

A melhor coisa que tem aqui são as pessoas, às vezes parece que é a estrutura, mas são as pessoas que fazem circular essa ideia que a gente tem aqui e daí todo mundo cresce, né, todo mundo nas suas diferentes áreas, diferentes funções, cresce aqui dentro, acho que era isso.

Cara, acho que é um relacionamento, bacana, de compartilhamento, de ajuda, de apoio, de aprendizado, de saber o que cada um faz, ver essa multidisciplinariedade que tem também, tem uma advogada, tem um arquiteto, tem um administrador, tipo 
eu também, essa relação é bacana, que a gente faz a gente olhar pro lado, faz a gente pensar um pouquinho fora da caixa, é bacana cara, vejo de uma maneira bem positiva essa, esse relacionamento, pode melhorar sempre, né, não conversei com todos aqui, ainda não tive contato, mas com a maioria já, então, bem positivo, bacana.

Quando perguntados "como você avalia as relações sociais aqui dentro do coworking?" os entrevistados também foram unânimes em colocar como sendo boas e mesmo ótimas as relações, como segue nas falas de dois dos entrevistados:

(...) eu avalio em termos de relação isso daqui é muito bom, se tivesse que dar uma nota às relações interpessoais aqui eu daria 10, sabe porque, ããa, a gente se soma em todos os sentidos, pro lado profissional, pessoal, ééé, pra negócios, pra oportunidades, ééé, sabe é muito assim, é muita coisa aqui, as relações, então assim aqui em termo de relações a gente, é muito bom assim, não sei muito o que falar, mas né.

Eu acho que as pessoas têm uma relação muito boa aqui, mas depende muito também da pessoa, sabe, se você tá, se você quer conversar com as pessoas, se você quer ter uma relação de conversa, de proximidade, de afeto é mais você que busca, eu acredito e não acredito que essa divisão dos lugares de trabalho ela interfere, por exemplo, pode uma pessoa que ela esteja trabalhando num escritório privado ela, ela tem uma relação boa com as outras pessoas, ela procura se aproximar, mas também vejo pessoas desse escritório privado não querer se aproximar, conversar, ou sabe, simplesmente um bom dia, mas em geral as pessoas aqui tem uma boa relação assim.
Alguns coworkers relatam que existem regras implícitas que também colaboram para este sentimento de compartilhamento e de pertencimento ao coworking, regras de convivência que influem diretamente na necessidade de ser socialmente competente, como por exemplo a regra de lavar a louça que usa, ou mesmo manter o silêncio. Seguir estas regras do local também pode estar associado com a HS de Civilidade (Del Prette \& Del Prette, 2017), relatadas por dois coworkers diferentes.

(...)porque você tem uma estrutura aqui que te lembra que você tá trabalhando, tem pessoas que precisam do teu silencio, pessoas que precisam da tua concentração também, porque se você não se concentra, você atrapalha o trabalho do outro, então até com isso você melhora o teu trabalho por precisar não atrapalhar o do outro, o que em casa você não faria, (...).

(...)por exemplo existem umas regras aqui que não são ditas mas a gente sabe que existem, se eu deixei a minha xicara lá na cozinha, é porque eu não me importo que alguém pegue ela e use, se eu não quero que ninguém pegue ela eu deixo ela aqui, né.

Todos os entrevistados relataram que conseguem se concentrar melhor no ambiente do coworking, o que colabora para que cada um dos coworkers consiga alcançar seus objetivos:

(...)mas aqui eu consigo me concentrar mais porque não tem as distrações de um home office, então aqui eu consigo me concentrar e por isso o trabalho rende mais, e na relação do pessoal, eu consigo estar melhor aqui assim, porque eu não tenho as preocupações que o home office traz, porque você estando em casa você tem as preocupações da casa, as preocupações do lar, da família ali muito próximas a ti. 


\section{Discussão}

Senso de comunidade é algo que foi identificado anteriormente nos coworking nos EUA. Comunidade pode ser entendida como um grupo de pessoas que discutem e tomam decisões juntas e que seguem determinadas práticas, sendo que estas definem a comunidade: aqueles que compartilham desses costumes, tornam-se parte da comunidade gerando melhorias na saúde psicológica e no bem-estar das pessoas que dela participam, suprindo também a necessidade de manter proximidade com outros seres humanos (Garrett, Spreitzer \& Bacevice, 2017). A respeito disso, observa-se este senso de comunidade a partir da seguinte fala:

(...)ontem quando tu me perguntaste, é, se a gente colaboraria contigo, eu fiquei pensando "como que eu vou trabalhar aqui e não vou colaborar com uma pessoa que tá aqui", né, eu estou aqui para colaborar, eu dependo que as pessoas daqui também tenham essa cultura.

Também pode-se entender que o coworking é um lugar adequado para o surgimento de um senso de comunidade quando se observa a sua estrutura e forma de funcionamento: um coworking é projetado para favorecer a interação em grupo, não necessariamente a produtividade e ou uma melhor performance de trabalho; a estrutura normativa e burocrática do coworking é a menor possível, o que permite que as pessoas venham e vão como se sentirem mais confortáveis, sendo que essa estrutura física também facilita a interação e a construção conjunta de um senso de comunidade, sendo que as relações mais horizontais colaboram muito para isso (Garrett et al., 2017).

Quando falamos de coworking, se entende que o valor está nas companhias, em quem mais faz parte desse coworking. Muitos espaços nos EUA designaram pessoas para trabalhar com os coworkers no sentido de formar uma comunidade, como se esta pessoa fosse um "administrador de comunidade". Este tem o foco em estruturar a comunidade, facilitar apresentações e manejar relações externas, de forma a buscar uma integração das necessidades do meio fora do coworking com as possibilidades e conhecimentos dos coworkers (Spinuzzi, 2012).

A criação de um senso de comunidade em termos de coworking se dá quando as pessoas são estimuladas progressivamente a internalizar as regras do local e este processo pode ser facilitado por um curador, alguém que estimule os coworkers a trocar e compartilhar das mais diferentes formas possíveis. Neste viés, o coworking pode ser entendido como um local de aprendizado social em um determinado espaço, onde as identidades individuais e coletivas são produzidas através da participação, criação e práticas sociais de compartilhamento do conhecimento (Gandini, 2015).

Observa-se que no coworking em que foi realizada a presente pesquisa, esta ideia de formar uma comunidade já está sendo implantada, sendo iniciativa da própria administração do local que funciona como um curador que trabalha tanto através de incentivo para a exposição de cada um do coworkers, (HS falar em público) como forma de compartilhamento de ideias e conhecimentos, quanto dedica-se a ensinar as práticas que compõem o local, como manter o silêncio (HS de civilidade).

Quando as pessoas trabalham juntas, elas aderem a uma participação periférica legítima, que as habilita a construir uma comunidade de coworking. Ao fazerem isso, aprendem a desenvolver um leque de práticas colaborativas diárias que as levam a um senso de empreendedorismo. No processo, os coworkers aprendem como ser colaborativos, proativos e a como contestar também o meio em que estão inseridos aprendendo, assim, a lidar com as incertezas da sua condição de trabalho, ganhando suporte e desenvolvendo um terreno favorável através da construção conjunta de um senso de comunidade (Gandini, 2015). 
Além disso, esse aprendizado ajuda os coworkers a desenvolver práticas que criam um senso coletivo de propósito e assim realça as suas habilidades individuais para se tornarem melhores empreendedores. Existe um escopo de aprendizados que devem ocorrer através da apropriação das práticas diárias para construir identidades ocupacionais com incertezas e condições precarizadas. $\mathrm{O}$ aprendizado no coworking também acontece quando os coworkers se apropriam desse espaço flexível em suas práticas. A forma como fazemos as coisas diariamente nos faz ser quem somos, e com isso as práticas inconscientemente se manifestam como valores sociais e hábitos, através de repetições cotidianas (Pohler, 2012).

Outra forma de se entender o coworking seria como sendo um local de trabalho sem fronteiras, onde se pode testar ideias, modelos alternativos de negócios, práticas de nova economia ou estruturas cooperativas flexíveis através do aprendizado e da troca colaborativa. Se destaca a proximidade física entre os coworkers como algo que produz oportunidades de combinação de conhecimentos de diferentes áreas (WatersLynch \& Potts, 2017).

Apenas a proximidade social não é suficiente para criar as interações e a transmissão de conhecimento necessárias para a inovação, além disso, uma plataforma organizacional é necessária. Ainda, é necessário que as pessoas aprendam a participar no coworking. Para ajudar nisso, os coworking promovem momentos onde os coworkers podem se conhecer, identificar interesses em comum, eventos sociais e promover apresentações (Waters-Lynch \& Potts, 2017).

A criação de uma comunidade no coworking possui três estágios, sendo a formação de uma identidade coletiva, a criação e cumprimento de normas, e por fim, o adotar e divulgar essa visão de trabalho. Aqueles que não se adequam as normas da comunidade do coworking acabam por sair, o que demonstra que o coworking tem uma seleção natural, pois para se tornar um membro total da comunidade, é necessário que se participe das práticas diárias, assim como as relações sociais e processos de criação e produção (Butcher, 2018).

A participação é necessária para se aprender o que é aceitável, o que não é e como discernir entre esses dois aspectos dentro do coworking, e nesse sentido um curador faz um papel essencial de inserir os novos coworkers gradualmente nas práticas diárias do coworking. Aprender a trabalhar em um coworking pode ser entendido como um processo onde indivíduos são convidados diariamente a compartilhas de práticas coletivas. Esse aprendizado está inserido nas socializações que ocorrem no coworking, aproximando mais os coworkers da ideia e da prática diária de coworking (Butcher, 2018).

Os benefícios diretos de um coworking são interação, feedback, confiança, aprendizado, companheirismo, encorajamento e o fato de tornar-se referência a outros profissionais, o que demonstra que o valor de um coworking está nas relações que as pessoas estabelecem ali. Além disso, o profissional tem a oportunidade de descobrir novos talentos e aprender diferentes formas de solução de problemas, através do compartilhamento propiciado pelo coworking (Spinuzzi, 2012). As razões para trabalhar em um coworking são complexas e motivadas por um desejo comum de aprender como construir carreiras individuais de empreendedorismo nas mais insertas e diversas situações (Pohler, 2012).

Por outro lado, trabalhar em casa potencializa $\mathrm{o}$ isolamento $\mathrm{e}$ dificulta $\mathrm{a}$ diferenciação entre trabalho e vida pessoal. Trabalhar sozinho pode fazer muitas pessoas se afastarem dos relacionamentos de trabalho com outros profissionais, além de perderem a oportunidade de criar laços de confiança, limitando seu acesso à infraestrutura (Spinuzzi, 2012).

A atual geração de profissionais possui a característica da flexibilidade, como a possibilidade de trabalhar em qualquer lugar com o celular, tablet, ou mesmo com o 
computador. Mas essa flexibilidade não é totalmente positiva, pois muitas vezes isto acaba gerando isolamento, perda de capacidade de construir relações de confiança, perda de oportunidades de network e perda de vivências de colaboração (Spinuzzi, 2012), o que também aponta uma dificuldade de desenvolver habilidades sociais.

Um baixo desenvolvimento de HS tende a estar associado com estados de sofrimento psíquico como a depressão, que tem como uma de suas consequências a tristeza. $\mathrm{O}$ desenvolvimento e aplicação de HS ajudam as pessoas a reduzir o humor deprimido no momento em que potencializam as interações sociais e diminuem a absorção do estresse e as respostar punitivas de outras pessoas (Feitosa, 2013).

O déficit de HS pode ser considerado um agravante para a depressão, no sentido de que a pessoa que é exposta a situações de estresse e não tem suas HS bem desenvolvidas, acaba lidando com isso de forma pouco funcional. Porém, também pode-se entender que pessoas com quadros depressivos tem uma predisposição a evitar a interação e isso resulta em déficit nas HS (Fernandes, Falcone \&Sardinha, 2012).

A carência de HS ocorre em diversos problemas psicológicos tais como estresse interpessoal, abuso de álcool e drogas, esquizofrenia, transtorno de ansiedade, transtorno de personalidade, entre outros. Em relação ao déficit em HS com os problemas psicológicos, pode-se analisar de três formas: (1) Problema psicológico como causa: quando em função da depressão uma pessoa se afasta do convívio com outras pessoas; (2) Problema psicológico como consequência: quando a pessoa possui baixa competência social, tem menos estímulos positivos e mais dificuldade de lidar com críticas e agressões, ficando mais estressada; (3) Problema psicológico e déficit em HS concomitantemente desencadeiam a depressão (Feitosa, 2013).

As pessoas que têm maior desenvolvimento de suas HS têm uma inclinação à satisfação geral com a vida, pois se afetam menos com estresse, o que demonstra que elas possuem pensamentos e sentimentos propícios que lhes permitem agir habilmente. Isto evidencia a relação entre saúde mental e habilidades sociais, pois pessoas com déficit de HS acabam sofrendo mais, o que pode ser um agravante de transtornos mentais, podendo até ser a gênese dessas patologias (Feitosa, 2013). As HS são, portanto, uma ferramenta importante para a saúde mental, uma vez que pessoas com elaborado repertório social têm menos sintomas depressivos, menores níveis de estresse e também podem contar com o apoio de outras pessoas as quais possuem uma relação de confiança. As experiências de amizade também estão diretamente relacionadas a percepção de um bem-estar do indivíduo (Del Prette \& Del Prette, 2017).

No ambiente de trabalho, as HS são consideradas um fator que influi no sucesso da atividade, sendo que são uteis, pois permitem estabelecer relações interpessoais satisfatórias, o que pode contribuir para a eficiência da realização de um trabalho. As HS são vistas como um componente chave para o trabalho em equipe, para a resolução de conflitos e para trabalhar de maneira mais coordenada, cooperativa e integrada com todos, além de cumprir um papel essencial na reflexão da percepção interpessoal e a capacidade de ajustar o comportamento às diferentes demandas (Veloso-Besio, Cuadra-Peralta, GilRodríguez, Quiroz-Cornejo, \& Meza-Castro, 2015).

As HS podem contribuir para o aumento da satisfação com a vida ao fortalecer os vínculos entre as pessoas, o que pode servir de rede de apoio quando a pessoa necessitar. Também o real empenho e comprometimento do sujeito nas mais diferentes atividades é necessário para se ter comportamentos assertivos para agir no meio, o que é possível através da prática diária das HS, ou seja, sentir emoções positivas e dar-se bem com os demais pode gerar um clima melhor no ambiente de trabalho. Em geral a emissão de comportamentos assertivos no trabalho gera atitudes positivas dos outros, o que traz um 
impacto positivo para o próprio sujeito, que mantendo essas atitudes se realizará mais durante a execução de suas tarefas (VelosoBesio et al., 2015).

As HS colaboram para que o sujeito de adapte melhor ao meio em que está se inserindo, de forma a assegurar sua integridade física e bem-estar psicológico. Porém, essa adaptação não é igual para homens e mulheres. O nível de HS pode variar conforme o gênero e conforme a formação do profissional, mas os homens geralmente são reconhecidos por sua assertividade, ao passo que as mulheres são reconhecidas por sua afetividade (Soares, Mourão, Santos, \& Mello, 2015).

Isto também é demonstrado nas entrevistas, em que as participantes relatam muito um sentimento de pertencimento e uma grande demonstração de afeto, principalmente com outras mulheres, o que também as auxiliava e muito no trabalho. Os homens entrevistados geralmente se colocavam de forma mais assertiva, porém não tão cooperativa, trabalhando cada um em sua função sem grandes trocas com outros coworkers.

\section{Considerações finais}

Considerando-se o desenvolvimento de habilidades sociais como algo essencial para qualquer relação humana, surge a possibilidade de atuação do psicólogo no sentido de realizar treinamentos em habilidades sociais, palestras e workshops voltados para os coworkers. Também podem os espaços coworking promover o desenvolvimento de habilidades sociais de seus coworkers, auxiliando-os no seu processo de aperfeiçoamento profissional e interpessoal. O psicólogo pode ser promotor desse processo, auxiliando no desenvolvimento dessas habilidades sociais.

Um coworking, por ser um ambiente coletivo de trabalho, exige interação das pessoas e para que essas interações sejam adequadas é necessário que cada um dos coworkers desenvolva suas habilidades sociais, para que se possa trabalhar de forma mais harmônica. Parece ser necessário que a pessoa que queira trabalhar em um coworking já tenha algumas habilidades sociais desenvolvidas previamente, principalmente as de assertividade, porém, a própria convivência no coworking pode virar um motor de desenvolvimento de habilidades sociais, de forma que se a pessoa estiver disposta, ela consegue extrair muito da experiência de ser um coworker, de compartilhar recursos e trocar experiências, e para isso também é fundamental o desenvolvimento da HS de comunicação.

No coworking em que foi realizada esta pesquisa, pode-se observar que as relações se dão em diferentes níveis de proximidade, desde um simples "bom dia" ao entrar no coworking, até o suporte emocional em momentos de crise. No aspecto geral, essas relações interpessoais foram descritas como agradáveis, boas e importantes para os coworkers, demonstrando serem de boa qualidade, o que essencialmente depende das habilidades sociais dos indivíduos.

Dentre as fragilidades desta pesquisa, pode-se apontar o fato de ter sido aplicada em apenas um coworking, o que impediu verificar possíveis especificidades de outros espaços. Também não foram entrevistados profissionais de todas as áreas presentes no local, o que poderia ter mostrado outros vieses das relações interpessoais no coworking. Desta forma, os resultados devem ser generalizados com cautela, pois este estudo tratou de apenas um espaço coworking, sem trabalhar uma amostra considerável de coworkers.

Apesar disso, este estudo pode contribuir para o reconhecimento e entendimento dos espaços coworking, na medida em que este é um tema recente e pouco estudado no Brasil, sendo que o cruzamento teórico entre as temáticas de habilidades sociais e coworking ainda não possuía uma pesquisa até o início de 2019. Observa-se que a formação de comunidades a partir dos espaços coworking realmente condiz com os estudos nos Estados Unidos e Inglaterra, o que também aponta uma tendência internacional de campo de pesquisa aplicável à realidade brasileira. 
Este estudo pode ajudar tanto coworkers, proprietários de coworking e mesmo psicólogos que percebam a importância e queiram trabalhar com Treinamento de Habilidades Sociais, visto que o desenvolvimento de habilidade sociais pode ser muito importante para todos que estão em um coworking. É necessário que os proprietários de coworking atentem para seus coworkers, de forma a estimulá-los a vivenciar a experiência de trocas e sentimento de comunidade, o que colabora para as relações, a saúde mental e também para o desenvolvimento dos negócios das pessoas que ali estão trabalhando.

Sugere-se para futuros estudos, a realização de pesquisas sobre a construção do sentimento de comunidade e pertencimento nos espaços coworking no Brasil, dado que poucas pesquisas foram realizadas nesse âmbito e o coworking é uma tendência mundial. Além disso, sugere-se a realização de mais pesquisas qualitativas com os coworkers, de forma a entender melhor as relações interpessoais nos diferentes locais espalhados pelo Brasil. Também se indica a aplicação do Inventário de Habilidades Sociais (Del Prette \& Del Prette, 2001), com os coworkers de outras localidades do Brasil a fim de entender o perfil do coworker brasileiro $\mathrm{e}$ as suas necessidades e potencialidades em termos de habilidade sociais, o que poderia ser realizado através de coletas online, o que também facilitaria o acesso a estes profissionais.

\section{Referências}

Bardin, L. (1977). Análise de conteúdo. Lisboa: Edições 70.

Beck, J. S. (2013). Terapia cognitivocomportamental: teoria e prática. Porto Alegre: Artmed.

Butcher, T. (2018) Learning everyday entrepreneurial practices through coworking. Management Learning. 49, 327-345. Recuperado de https://journalssagepubcom.ez127.periodicos.capes.gov.br/doi/pdf/ 10.1177/1350507618757088

Caballo, V. E. (2003) Manual de avaliação e treinamento de habilidades sociais. São Paulo: Livraria Santos Editora.

Carlomagno, M. C., \& Rocha, L. C. da (2016). Como criar e classificar categorias para fazer análise de conteúdo. Revista Eletrônica de Ciência Política, 7, 1. Recuperado de https://revistas.ufpr.br/politica/article/view/ 45771/28756

Coworking Brasil (2018). Apresenta informações gerais sobre o coworking no Brasil. Recuperado de https://coworkingbrsil.org/censo/2018/?itm =topbar\#gestao

Del Prette, A., \& Del Prette, Z. A. P. (2001). Psicologia das relações interpessoais: vivências para o trabalho em grupo.

Petrópolis: Editora Vozes.

Del Prette, A., \& Del Prette, Z. A. P. (2017). Competência Social e Habilidade Social: manual teórico-prático. Petrópolis: Editora Vozes.

Feitosa, F. B. (2013). Habilidades sociais e sofrimento psicológico. Arquivos

Brasileiros de Psicologia. 65, 38-50.

Recuperado de http://pepsic.bvsalud.org/pdf/arbp/v65n1/v6 5n1a04.pdf

Fernandes, C. S., Falcone, E. M. O., \& Sardinha, A. (2012). Deficiências em habilidades sociais na depressão: estudo comparativo. Psicologia: teoria e prática. 14, 183-196. Recuperado de http://pepsic.bvsalud.org/pdf/ptp/v14n1/v14 n1a14.pdf

Gandini, A. (2015). The rise of coworking spaces: A literature review. Ephemera, 15, 193-205. Recuperado de http://www.ephemerajournal.org/contributi on/rise-coworking-spaces-literature-review

Garrett, L. E., Spreitzer, G. M., \& Bacevice P. A. (2017). Co-constructing a Sense of Community at Work: The Emergence of Community in Coworking Spaces.

Organization Studies. 38, 821-842. Recuperado de https://journals-sagepub- 
com.ez127.periodicos.capes.gov.br/doi/full/ $10.1177 / 0170840616685354$

Global Entrepreneurship Monitor. (2014). Empreendedorismo no Brasil 2015.

Curitiba: IBQP. Recuperado de http://cer.sebrae.com.br/wpcontent/uploads/2015/12/7347.pdf

Minayo, M. C. de S. (2014). O desafio do conhecimento: pesquisa qualitativa em saúde. São Paulo: Hucitec.

Nakao, B., \& Mussi, C. C. (2018). Uma nova configuração do trabalho: análise Interpretativa da literatura de coworking. CONTEXTUS: Revista Contemporânea de Economia e Gestão. 16, 53-89. Recuperado de

http://periodicos.ufc.br/contextus/article/vie w/33165/73223

Pohler, N. (2012). Neue Arbeitsräume für neue Arbeitsformen: Coworking Spaces. Forschungsnotiz 37, 65-78. Recuperado de https://link-springercom.ez127.periodicos.capes.gov.br/content/ pdf/10.1007\%2Fs11614-012-0021-y.pdf

Soares, A. B., Mourão, L., Santos, A. A. A., \& Mello, T. V. S. (2015). Habilidades Sociais e Vivência Acadêmica de Estudantes Universitários. Interação Em Psicologia, 19(2), 211-223. Recuperado de https://revistas.ufpr.br/psicologia/article/vie w/31663/29355

Spinuzzi, C. (2012). Working Alone Together: Coworking as Emergent Collaborative Activity. Journal of Business and Technical Communication. 26, 399-441. Recuperado de https://journals-sagepubcom.ez127.periodicos.capes.gov.br/doi/pdf/ 10.1177/1050651912444070

Veloso-Besio, C., Cuadra-Peralta, A., GilRodríguez, F., Quiroz-Cornejo, A. \& MezaCastro, S. (2015). Capacitación en trabajadores: impacto de un programa, basado en psicología positiva y habilidades sociales, en satisfacción vital, satisfacción laboral y clima organizacional. Interciencia, 40(11), 736743. Recuperado de https://www.redalyc.org/articulo.oa? $\mathrm{id}=339$ $\underline{42541002}$

Waters-Lynch, J., \& Potts, J. (2017). The social economy of coworking spaces: a focal point model of coordination. Review of Social economy. 75, 417-433.

Recuperado de http://web-aebscohost.ez127.periodicos.capes.gov.br/eh ost/pdfviewer/pdfviewer?vid=1\&sid=10b5f fc6-d379-4b0b-ab5ed5125324cab6\%40sessionmgr4007

\section{Dados sobre os autores:}

- Luís Augusto Bohnenberger: Bacharel em Psicologia pela Universidade de Santa Cruz do Sul.

- Marina Pante: Doutora em Psicologia. Professora do Curso de Psicologia da Universidade de Santa Cruz do Sul.

\footnotetext{
Declaração de Direito Autoral

A submissão de originais para este periódico implica na transferência, pelos autores, dos direitos de publicação impressa e digital. Os direitos autorais para os artigos publicados são do autor, com direitos do periódico sobre a primeira publicação. Os autores somente poderão utilizar os mesmos resultados em outras publicações indicando claramente este periódico como o meio da publicação original. Em virtude de sermos um periódico de acesso aberto, permite-se o uso gratuito dos artigos em aplicações educacionais e científicas desde que citada a fonte conforme a licença CC-BY da Creative Commons.
} 